\title{
Hubungan Tingkat Kecemasan dengan Kualitas Tidur pada Lansia yang Mengalami Insomnia
}

\author{
Nirwana Latif $^{\text {a }}$, Susilaningsih ${ }^{\mathrm{b}}$, Rahmawati Maulidia ${ }^{\mathrm{c}}$ \\ aProdi Sarjana Keperawatan, STIKes Maharani, Malang, Indonesia \\ ${ }^{b}$ Prodi Sarjana Keperawatan, Poltekes Kemenkes, Malang, Indonesia \\ ${ }^{c}$ Prodi Analis Kesehatan, STIKes Maharani, Malang, Indonesia \\ Email Korespondensi: Nirwanlatief@gmail.com
}

\begin{abstract}
Introduction: The raising number of elderly will cause various health problems, such as sadness, feeling useless, feeling stress, depression, anxiety and sleeping disorder, such as insomnia, which is caused by various factors. The purpose of this study is to find out the correlation between anxiety level and sleep quality in elderly with insomnia at RAAL Griya Asih Lawang Kabupaten Malang. Method: This study used correlational analytic method with cross-sectional approach. Population in this study were all elderlies who experienced insomnia (40 respondents). Using total sampling technique, the sample used were 40 respondents. The research instrument was questionnaire. Results: From this study, it was obtained most of the respondents experienced poor sleeping quality and had severe anxiety; 27 respondents (67.5\%). The data analysis in this study used Spearman test which showed that the correlation value of 0.819 which means that both variables have strong correlation. $p$ value was 0.000 . It means $\mathrm{HO}$ was rejected and $\mathrm{H} \mathrm{l}$ was accepted. Conclusion: This explained that there was correlation between anxiety level and sleep quality on elderly with insomnia. Suggestion: the elderly can reduce anxiety affecting the sleep quality by actively doing positive activities such as exercise, which can relieve anxiety and get good sleep quality.
\end{abstract}

Keywords: Anxiety, Sleep Quality, Insomnia

\begin{abstract}
Abstrak
Pendahuluan: Peningkatan jumlah lanjut usia akibat peningkatan usia harapan hidup akan menyebabkan berbagai masalah di bidang kesehatan seperti mudah sedih, merasa tidak berguna, stress, depresi, kecemasan dan mengalami gangguan tidur seperti insomnia yang diakibatkan oleh berbagai faktor. Tujuan penelitian untuk mengetahui hubungan antara tingkat kecemasan dengan kualitas tidur pada lansia yang mengalami insomnia di Raal Griya Asih Lawang Kabupaten Malang. Metode: Penelitian ini menggunakan metode analitik korelasional dengan pendekatan croos-sectional. Populasi adalah semua lansia yang mengalami insomnia sebanyak 40 responden. Teknik sampling menggunakan total sampling jadi besar sampel 40 responden. Instrumen penelitian menggunakan koesioner. Hasil: Dari penelitian ini, sebagian besar responden yang mengalami kualitas tidur buruk dan memiliki tingkat kecemasan yang berat yaitu 27 responden $(67.5 \%)$. Analisis data pada penelitian ini menggunakan uji Spearman yang menunjukan bahwa Nilai korelasi 0.819 yang artinya kedua variabel memiliki hubungan yang kuat dan nilai p 0,000. Yang berarti H0 ditolak dan H1 diterima. Kesimpulan: Kesimpulan penelitian ada hubungan antara tingkat kecemasan dengan kualitas tidur pada lansia yang mengalami insomnia. diharapkan lansia dapat mengurangi kecemasan yang berdampak pada kualitas tidur dengan cara aktif melakukan kegiatan-kegiatan positif misalnya berolahraga, yang dapat menghilangkan rasa cemas dan mendapatkan kualitas tidur yang baik.
\end{abstract}

Latif, N., dkk., Hubungan Tingkat Kecemasan dengan Kualitas Tidur 
PROFESIONAL HEALTH JOURNAL

Volume 2, No. 1, Desember 2020 (Hal. 1-8)

https://www.ojsstikesbanyuwangi.com/index.php/PHJ

Kata kunci: Kecemasan, Kualitas tidur, Lansia.

\section{PENDAHULUAN}

Kecemasan merupakan kecemasan dan kekawatiran yang berlebihan terhadap sejumlah aktifitas atau peristiwa yang berlangsung hampir setiap hari, selama 6 bulan atau lebih. Penyakit ini sering terjadi, dimana sekitar 3-5 orang dewasa pernah mengalaminya dan 2 kali lebih sering terjadi pada wanita. Pada umumnya penyakit ini berawal saat anak-anak atau remaja. Kondisi penderita kerap berfluktuasi, semakin memburuk ketika mengalami stres dan menetap selama bertahun tahun. (Iskandar junaidi,2012).

Kecemasan bisa menimbulkan seseorang mengalami perasaan yang sulit dan aktivitas syaraf otonom dalam berespon terhadap ketidak berdayaan ancaman yang tidak spesifik. Pengaruh tersebut mengakibatkan terjadi suatu penyakit yang disebut sebagai insomnia karena insomnia merupakan penyakit, maka perhatian harus diberikan pada faktor-faktor biologis, emosional, dan medis yang berperan, juga pada kebiasaan yang buruk. Semua orang pernah mengalami gangguan tidur/kurang tidur/ kesulitan tidur (insomnia), tetapi biasanya hanya sementara saja. Gangguan ini menjadi masalah besar bila terjadi setiap malam dalam waktu lama dan terus menerus karna berakibat buruk terhadap kesehatan fisik dan jiwa misalnya, konsentrasi menurun (Yanuar \& Pamungkas, 2019), mudah marah,

depresi. Setiap orang mempunyai kebutuhan tidur yang berbeda. Tidur adalah suatu proses yang sangat penting bagi Latif, N., dkk., Hubungan Tingkat Kecemasan dengan Kualitas Tidur manusia, karena dalam tidur menjadi proses pemulihan, proses ini bermanfaat mengembalikan kondisi seseorang pada keadaan semula, dengan begitu, tubuh yang tadinya mengalami kelelahan akan menjadi segar kembali. Proses pemulihan yag terhambat dapat menyebabkan organ tubuh tidak bisa bekerja dengan maksimal, akibatnya orang yang kurang tidur akan cepat lelah dan mengalami penurunan konsentrasi. Kondisi tidur dapat memasuki suatu keadaan istirahat periodik dan pada saat itu kesadaran terhadap alam menjadi terhenti, hingga tubuh dapat beristirahat. Otak memiliki jumlah fungsi,struktur dan pusat-pusat tidur yang mengatur siklus tidur dan terjaga.tubuh pada saat yang sama menghasilkan substansi yang ketika dilepaskan kedalam aliran darah akan membuat mengantuk. Proses tersebut jika di ubah oleh stres,kecemasan, gangguan dan sakit fisik dapat menimbulkan insomnia (Carpenito, 2000 dan Ulumuddin, 2011).

Kecemasan yang dialami oleh lansia juga dapat menyebabkan kesulitan tidur serta dapat mempengaruhi kosentrasi dan kesiagaan, dan juga meningkatkan resikoresiko kesehatan (Dwidiyanti et al., 2018), serta dapat merusak fungsi sistem imun. Kekurangan tidur pada lansia memberikan pengaruh terhadap fisik, kemampuan kognitif dan juga kualitas hidup (Maryam $\mathrm{dkk}, 2012)$

\section{METODE}

Jenis penelitian yang digunakan pada penelitian ini adalah kuantitatif yang 
PROFESIONAL HEALTH JOURNAL

Volume 2, No. 1, Desember 2020 (Hal. 1-8)

https://www.ojsstikesbanyuwangi.com/index.php/PHJ

menggunakan desain penelitian deskriktif korelasi yaitu mencari hubungan antara tingkat kecemasan dengan kualitas tidur pada lansia yang mengalami insomnia. Pada penelitian ini menggunakan pendekatan cross-sectional, yaitu jenis penelitian yang menekankan waktu pengukuran/observasi data independen dan dependen hanya satu kali pada satu saat. Populasi dari penelitian ini adalah lansia yang mengalami insomnia. Jumlah populasi pada penelitian sebanyak 40 lansia yang mengalami tingkat kecemasan dengan kualitas tidur di Raal Griya Asih Lawang Kota Malang.

Kriteria Inklusi:

1. Lanjut usia yang berusia 60-75 tahun

2. Bisa berkomunikasi dengan baik

3. Lansia yang tidak buta huruf

4. Lansia yang mengalami insomnia

5. Lansia yang bersedia menjadi responden

\section{HASIL PENELITIAN}

\section{Karakteristik Responden Berdasarkan Usia}

Tabel 1. Distribusi frekuensi responden berdasarkan Usia di RAAL Griya Asih Lawang Kabupaten Malang

\begin{tabular}{ccc}
\hline Usia & Frekuensi & $\%$ \\
\hline $60-65$ & 2 & 5 \\
$66-70$ & 15 & 36 \\
$71-75$ & 23 & 59 \\
\hline Jumlah & 40 & 100 \\
\hline
\end{tabular}

Sumber: Data Primer, 2018

Berdasarkan data tabel 1, dari 40 responden didapatkan hasil bahwa sebagian

\section{Kualitas tidur pada lansia yang mengalami insomnia}

Tabel 4. Distribusi responden berdasarkan kualitas tidur pada lansia yang mengalami insomnia di RAAL besar responden berusia 71-75 tahun yaitu 23 responden $(59 \%)$.

\section{Karakteristik Responden Berdasarkan Jenis Kelamin}

Tabel 2. Distribusi frekuensi responden berdasarkan jeniskelamin di RAAL Griya Asih Lawang Kabupaten Malang

\begin{tabular}{lcc}
\hline Jenis Kelamin & Frekuensi & $\%$ \\
\hline Laki-laki & 0 & 0 \\
Perempuan & 40 & 100 \\
\hline Jumlah & 40 & 100
\end{tabular}

Sumber: Data Primer, 2018

Berdasarkan data tabel 2 dari 40 responden didapatkan hasil bahwa semua responden berjenis kelamin perempuan yaitu 40 responden $(100 \%)$.

\section{Tingkat kecemasan pada lansia yang mengalami insomnia}

Tabel 3. Distribusi responden berdasarkan tingkat kecemasan pada lansia yang mengalami insomnia di RAAL Griya Asih Lawang Kabupaten Malang

\begin{tabular}{ccc}
\hline $\begin{array}{c}\text { Tingkat } \\
\text { kecemasan }\end{array}$ & Frekuensi & $\%$ \\
\hline Ringan & 0 & 0 \\
Sedang & 3 & 7 \\
Berat & 27 & 68 \\
Panik & 10 & 25 \\
\hline Jumlah & 40 & 100 \\
\hline Sumber: Data Primer 2018 & &
\end{tabular}

Berdasarkan data tabel 3, dari 40 responden didapatkan hasil bahwa hampir seluruh responden mengalami tingkat kecemasan kategori berat yaitu 27 responden $(68 \%)$.

Griya Asih Lawang Kabupaten Malang

\begin{tabular}{lcc}
\hline Kualitas tidur & Frekuensi & $\%$ \\
\hline Baik & 9 & 25 \\
Buruk & 31 & 75 \\
\hline
\end{tabular}


PROFESIONAL HEALTH JOURNAL

Volume 2, No. 1, Desember 2020 (Hal. 1-8)

https://www.ojsstikesbanyuwangi.com/index.php/PHJ

Jumlah

40

100

Sumber: Data Primer, 2018

Berdasarkan data tabel 4, dari 40 responden didapatkan hasil bahwa sebagian besar responden dengan kualitas tidur kategori buruk yaitu 31 responden (75\%).

\section{Hubungan tingkat kecemasan dengan kualitas tidur pada lansia yang mengalami insomnia}

Tabel 5. Tabulasi silang hubungan tingkat kecemasan dengan kualitas tidur pada lansia yang mengalami insomnia

Berdasarkan data tabel 5, dapat diketahui bahwa dari 40 responden sebagian besar responden yang memiliki kualitas tidur buruk dan memiliki tingkat kecemasan yang berat yaitu 27 responden $(67,5)$.

Dari hasil di atas dapat di simpulkan bahwa semakin berat tingkat kecemasan maka semakin buruk kualitas tidur pada lansia.

\section{PEMBAHASAN}

Pada bab ini akan dibahas mengenai hasil pembahasan penelitian yang telah dilakukan tentang hubungan Tingkat Kecemasan Dengan Kualitas Tidur Pada Lansia Yang Mengalami Insomnia di raal griya asih lawang Kota Malang.

\section{Tingkat Kecemasan pada lansia yang mengalami insomnia di RAAL Griya Asih Lawang Kabupaten Malang}

Latif, N., dkk., Hubungan Tingkat Kecemasan dengan
Berdasarkan hasil penelitian terhadap 40 responden, tidak satupun dari responden yang tidak mengalami kecemasan, sangat sedikit responden yaitu tiga responden termasuk ke dalam kategori tingkat kecemasan sedang, sebagian besar responden yaitu 27 responden termasuk ke dalam kategori tingkat kecemasan berat, sebagian kecil responden yaitu 10 responden termasuk kategori tingkat kecemasan panik, dan tidak satupun responden yang termasuk ke dalam kategori tingkat kecemasan ringan.

Pernyataan kecemasan didukung dengan sebuah teori bahwa kecemasan merupakan kekhawatiran yang tidak jelas dan menyebar yang berkaitan dengan perasaan tidak pasti dan tidak berdaya. Keadaan emosi ini tidak memiliki obyek yang spesifik. Kecemasan dialami secara subjektif dan dikomunikasikan secara interpersonal. Kecemasan sangat akrab dengan kehidupan sehari-hari, yang menggambarkan keadaan khawatir, gelisah, dan tidak tentram disertai gangguan sakit, dengan arti kecemasan dapat menjadi bagian dari kualitas tidur, terutama pada lansia (Stuart, 2012).

Dari hasil data juga menunjukan bahwa sebagian besar responden yaitu 27 responden mengalami kecemasan berat. Kecemasan berat adalah kecemasan yang terlalu berat dan berakar secara mendalam dalam diri seseorang. Apabila seseorang mengalami kecemasan semacam ini maka biasanya ia tidak dapat mengatasinya. Kecemasan ini mempunyai akibat menghambat atau merugikan perkembangan kepribadian seseorang. Kecemasan ini dibagi menjadi dua yaitu 
kecemasan berat yang sebentar dan lama. Kecemasan yang berat tetapi munculnya sebentar dapat menimbulkan traumatis pada individu jika menghadapi situasi yang sama dengan situasi penyebab munculnya kecemasan. Sedangkan kecemasan yang berat tetapi munculnya lama akan merusak kepribadian individu. Hal ini akan berlangsung terus menerus bertahun-tahun dan dapat merusak proses kognisi individu. Kecemasan yang berat dan lama akan menimbulkan berbagai macam penyakit seperti darah tinggi, tachycardia (percepatan darah), excited (heboh, gempar).

Menurut peneliti, lanjut usia cenderung mengalami kecemasan karena banyak faktor yang mempengaruhi yaitu faktor internal: Usia, Sifat, Kepribadian, Kebudayaan, dan rasa takut. Sedangkan factor eksternal: Keluarga, Hubungan pribadi, Kehilangan kebebasan, Pendidikan, Pengetahuan, dan Pekerjaan. Hal inilah yang menyebabkan lanjut usia gampang mengalami kecemasan. Lansia juga kebanyakan mengalami beban hidup yang dibebani sendiri dan hilangnya kemampuan penglihatan, badan mulai membungkuk, sehingga menurunnya kemampuan untuk melakukan aktivitas hidup sehari-hari.

\section{Kualitas Tidur pada Lansia yang mengalami insomnia di RAAL Griya Asih Lawang Kabupaten Malang}

Hasil penelitian menunjukan bahwa sebagian dari responden yaitu sembilan responden $(25 \%)$ mengalami kualitas tidur yang baik dan sebagian lagi responden yaitu 31 responden $(75 \%)$ mengalami kualitas tidur yang buruk.
Kualitas tidur berarti kemampuan individu untuk dapat tidur tahapan REM dan NREM secara normal. Waktu tidur menurun dengan tajam setelah seseorang memasuki masa tua. Pada proses degenerasi yang terjadi pada lansia, waktu tidur efektif akan semakin berkurang. Sehingga tidak tercapai kualitas tidur yang adekuat dan akan menimbulkan berbagai macam keluhan tidur. Disamping itu juga, mereka harus menyesuaikan diri dengan perubahanperubahan secara fisik, fisiologis, dan psikologis yang cenderung bergerak ke arah yang lebih buruk (Kozier, 2010)

Hal ini didukung oleh hasil penelitian Khasanah (2012), yaitu sebagian besar responden berumur 60-74 sebanyak 75 responden dan yang memiliki kualitas tidur buruk berada pada usia 60-74 tahun sebanyak 49 responden. Artinya 65,3 \% mengalami kualitas tidur yang buruk. Seseorang mengalami penurunan pada fungsi organnya ketika memasuki masa tua yang mengakibatkan lansia rentan terhadap penyakit seperti nyeri sendi, osteoporosis, parkinson. Usia memiliki pengaruh terhadap kualitas tidur seseorang yang dikaitkan dengan penyakit yang dialami dan kesehatan yang buruk. Hal ini yang menyebabkan lansia mengalami gangguan tidur seiring dengan bertambahnya usia.

Hal ini sesuai teori bahwa intervensi keperawatan untuk kebutuhan tidur pada lansia yaitu dengan pola tidur bangun seperti pertahankan waktu bangun tidur yang teratur, kontrol lingkungan seperti jaga kebisingan tetap minimum, menggunakan medikasi, memperhatikan faktor fisiologis atau penyakit, serta perhatikan faktor psikologis dengan 
PROFESIONAL HEALTH JOURNAL

Volume 2, No. 1, Desember 2020 (Hal. 1-8)

https://www.ojsstikesbanyuwangi.com/index.php/PHJ

menggunakan tekhnik relaksasi (Potter \& Perry, 2005).

Menurut peneliti Gangguan tidur (insomnia) yang dapat menurunkan kualitas tidur pada lansia, kualitas tidur pada lansia juga di pengaruhi oleh beberapa faktor yaitu: Penyakit, kelelahan, lingkungan, Obat-obatan, Stres psikologi, Motivasi. Sehingga lansia cenderung mengalami kualitas tidur yang buruk. Hal ini karna kurangnya aktivitas-aktivitas di siang hari sehingga lansia mengalami ngantuk di siang hari, merasa lemas, cemas, dan gelisah sehingga sebagian besar responden yaitu 31 responden $(75 \%)$ mengalami kualitas tidur yang buruk.

Tidur tidak sekedar mengistirahatkan tubuh tetapi juga dengan otak dan pikiran. Dengan istirahatnya otak, diharapkan proses penyembuhan gangguan tidur menjadi normal dan kualitas tidur pada lansia membaik. Sehingga angka kejadian kualitas tidur semakin berkurang dan tidak ada lagi lansia yang mengalami kualitas tidur buruk.

\section{Hubungan Tingkat Kecemasan dengan kualitas tidur pada Lansia yang mengalami Insomnia di RAAL Griya Asih Lawang Kabupaten Malang}

Berdasarkan hasil penelitian hasil uji statistik dengan menggunakan korelasi Spearman Rank kemudian dianalisis dengan menggunakan fasilitas komputer program SPSS versi 16 dengan nilai $r$ sebesar 0,819 yang berarti bahwa kedua variabel memiliki hubungan yang kuat dan nilai $\mathrm{p}$ sebesar $0.000(\alpha<0,005)$. Hal ini menunjukan bahwa hipotesis yang diajukan diterima, yaitu Ho ditolak dan H1 diterima.
Berdasarkan kriteria uji tersebut maka dapat disimpulkan terdapat hubungan antara tingkat kecemasan dan kualitas tidur pada lansia yang mengalami insomnia di Raal Griya Asih Lawang Kota Malang.

\section{KESIMPULAN DAN SARAN}

Berdasarkan hasil penelitian dan pembahasan dapat diambil beberapa kesimpulan dari penelitian ini sebagai berikut:

1. Sebagian besar responden dengan tingkat kecemasan berat yaitu $(68 \%)$.

2. Sebagian besar kualitas tidur responden (75\%) mengalami kualitas tidur yang buruk.

3. Adanya hubungan antara tingkat kecemasan dengan kualitas tidur pada lansia yang mengalami insomnia di Raal Griya Asih Lawang Kota Malang, dengan nilai korelasi 0.819 yang menandakan bahwa kedua variabel memiliki hubungan yang kuat dan nilai $\mathrm{p}$ 0.000 (á < 0,001).

Berdasarkan hasil penelitian yang telah dilakukan ada beberapa hal yang perlu direkomendasikan untuk penelitian selanjutnya yang terkai dengan penelitian ini:

1. Bagi Profesi Keperawatan

Sebagai bahan masukan dalam upaya meningkatkan profesionalisme dan mutu pelayanan keperawatan, khususnya perawatan gerontik. Dan diharapkan dapat mengembangkan praktek klinik keperawatan profesional dengan lebih mengutamakan intervensi keperawatan mandiri yang dalam hal ini mampu memperhatikan juga masalah kecemasan yang dialami lansia dengan cara mengoptimalisasikan program kegiatan untuk para lansia. 
PROFESIONAL HEALTH JOURNAL

Volume 2, No. 1, Desember 2020 (Hal. 1-8)

https://www.ojsstikesbanyuwangi.com/index.php/PHJ

2. Bagi lansia

Lansia dapat melakukan kegiatakegiatan yang dapat menghilangkan rasa cemas dan mendapatkan hasil kualitas tidur yang baik untuk lansia yang mengalami insomnia.

3. Bagi RAAL Griya Asih Lawang

Diharapkan agar petugas kesehatan yang ditugaskan di Raal Griya Asih Lawang tidak hanya memperhatikan kesehatan fisik para lansia saja, tetapi harus memperhatikan juga masalah kecemasan yang dialami lansia dengan cara mengoptimalisasikan program kegiatan untuk para lansia. Dengan itu para lansia mempunyai aktifitas serta dapat mencegah rasa cemas dan mendapatkan hasil kualitas tidur yang baik.

4. Bagi Peneliti Selanjutnya

Bagi penelitian selanjutnya, penelitian ini hanya terbatas pada tingkat kecemasan dan kualitas tidur saja sehingga perlunya kajian yang lebih mendalam mengenai faktor-faktor yang mempengaruhi kecemasan lansia dan kualitas tidur lansia.

\section{DAFTAR RUJUKAN}

Amir, N. (2007). Gangguan Tidur pada Lanjut Usia, Diagnosis dan Penatalaksanaan. Jurnal Cermin Dunia Kedokteran.

Arkunto, Suharsimi. (2013). Prosedur Penelitian: Suatu Pendekatan Praktik. Cetakan Kelima belas. Jakarta: Pustaka Belajar.

Asmadi, (2009). Tekhnik Prosedural Keperawatan Konsep dan Aplikasi Kebutuhan Tidur. Jakarta: Salemba Medika.
Fajar. (2009). Statistik Untuk Praktisi Kesehatan. Yogyakarta: Graha Ilmu.

Ghaddafi, M. Tatalaksana Insomnia dengan Farmakologi atau non-farmakologi. EJurnal Medika Udayana tidak ada vol, tahun, dll.

Hardiwinoto. (2010). Panduan Gerontologi Tinjauan dari Beberapa Aspek. Jakarta: PT. Gramedia Pustaka Utama.

Kaplan, H.I., Sadock, B.J dan Grebb, J. A., (1998). Sinopsis Psikiatri, Ilmu Pengetahuan Prilaku Psikiatri Klinis, Edisi 7. Jilid II. Jakarta: Binarupa Aksara.

Khasanah. (2012). Faktor-Faktor yang Berhubungan dengan Kualitas Tidur Lansia di Panti Sosial Trisna Werdha Melania Tangerang. Skripsi. UPN Veteran.

Kozier. Erb, Berman. Snyder. (2010). Buku Ajar Fundamental Keperawatan: Konsep, Proses \& Praktik;Edisi 7; Vol 2. Jakarta: EGC.

Maryam, R. Siti, Mia, Fatma Ekasari, Rosdiawati, Ahmad Jubaedi \& Irwan Batu Bara. (2012). Mengenal Usia Lanjut dan Perawatannya. Jakarta: Salemba Medika.

Mickey, Stanley, (2007). Buku Ajar Keperawatan Gerontik; Ed. 2. Jakarta: EGC

Mujahidullah, Khalid. (2012). Keperawatan Geriatrik Merawat Lansia dengan Cinta dan Kasih Sayang. Yogyakarta: Pustaka Pelajar.

MuhibinSyah. (2006). Psikologi Belajar. Bandung: Rajawali Pers. 
PROFESIONAL HEALTH JOURNAL

Volume 2, No. 1, Desember 2020 (Hal. 1-8)

https://www.ojsstikesbanyuwangi.com/index.php/PHJ

Slameto. (2010). Belajar dan FaktorFaktor yang Mempengaruhinya. Jakarta: Rineka Cipta.

Nadorff, M.R.,A. Fiske, J.A. Sperry, R Petts, J.J Gregg. (2013). Insomnia Symptoms, Nightmare and Suicidal Ideation in Older Adults. The jurnal of genorology. (vol, nomer, dll tidak ada)

Nursalam. (2008). Konsep dan Penerapan Metodologi Penelitian Ilmu Keperawatan Pedoman Skripsi, Thesis, dan Instrumen Penelitian Keperawatan (Edisi 2). Jakarta: Salemba Medika.

Nursalam. (2013). Metodologi Penelitian Kesehatan. Jakarta: Rineka Cipta.

Notoatmodjo. (2003). Pendidikan dan Perilaku Kesehatan. Jakarta: Rineka Cipta.

Notoatdmodjo, Soekidjo. (2012). Metodologi Penelitian Kesehatan. Jakarta: Rineka Cipta.

Padila. (2013). Buku Ajar Keperawatan Gerontik. Yogyakarta: Nuha Medika.

Potter, P.A, erry, A.G. (2005). Buku Ajar Fudamental Keperawatan: Konsep, Proses, dan Praktik, Edisi 4, Volume 2. Alih Bahasa: Renata Komalasari, dkk. Jakarta: EGC.

Purwanto. (2012). Metode Penelitian Kuantitatif. Yogyakarta: Penerbit Gavamedia.

Puspitosari, (2010). Gangguan Pola Tidur pada Kelompok Usia Lanjut. Journal Kedokteran Trisakti. Januari-April vol. 21, no. 1.

Susilo, Yekti \& Wulandari, Ari, (2011). Cara Jitu Mengatasi Insomnia, Yogyakarta: Andi Offset.
Stuart, G.W. (2012). Buku Saku Keperawatan Jiwa, Edisi 5. Jakarta: EGC.

Sugiyono. (2014). Statistik untuk Peneliti. Bandung: Alfabeta.

Setiadi. (2013). Konsep dan Praktek Penulisan Riset Keperawatan. Edisi Yogyakarta: Graha Ilmu.

Dwidiyanti, M., Pamungkas, A. Y. F., \& Ningsih, H. E. W. (2018).

Mindfulness caring pada stress (1st ed.). UNDIP Press.

Yanuar, A., \& Pamungkas, F. (2019).

Hubungan Dukungan Sosial dengan Tingkat Stres pada Warga Binaan Pemasyarakatan Perempuan di Lembaga Pemasyarakatan. 2(2), 4247. 